\begin{tabular}{|l|l|l|l|l|}
\hline \multirow{2}{*}{ aptara } & JMI & jmi_2095 & Dispatch: 8-16-2008 & CE: \\
\cline { 2 - 5 } & Journal & MSP No. & No. of pages: 8 & PE: Philippa \\
\hline
\end{tabular}

\title{
Non-invasive, label-free cell counting and quantitative analysis of adherent cells using digital holography
}

\author{
A. MÖLDER*, M. SEBESTA*, M. GUSTAFSSON†, \\ L. GISSELSON*, A. GJÖRLOFF WINGREN \\ $\& \mathrm{~K} \cdot \mathrm{ALM}_{\S}$ \\ *Phase Holographic Imaging AB, Lund, Sweden \\ $\dagger$ Electrical and information technology, Lund University, Lund, Sweden \\ $\ddagger$ Department of Biomedical Laboratory Science, Health and Society, Malmö University and Malmö \\ University Hospital, Malmö, Sweden \\ $\S$ Cell and Organism Biology, Lund University, Lund, Sweden
}

Key words. ???

\begin{abstract}
Summary
Manual cell counting is time consuming and requires a high degree of skill on behalf of the person performing the count. Here we use a technique that utilizes digital holography, allowing label-free and completely non-invasive cell counting directly in cell culture vessels with adherent viable cells. The images produced can provide both quantitative and qualitative phase information from a single hologram. The recently constructed microscope Holomonitor ${ }^{\mathrm{TM}}$ (Phase Holographic Imaging $\mathrm{AB}$, Lund, Sweden) combines the commonly used phase contrast microscope with digital holography, the latter giving us the possibility of achieving quantitative information on cellular shape, area, confluence and optical thickness. This project aimed at determining the accuracy and repeatability of cell counting measurements using digital holography compared to the conventional manual cell counting method using a haemocytometer. The collected data were also used to determine cell size and cellular optical thickness. The results show that digital holography can be used for non-invasive automatic cell counting as precisely as conventional manual cell counting
\end{abstract}

\section{Introduction}

Despite technical advances, one of the most versatile and powerful methods for cellular analysis is still visual analysis. However, manual examination and counting are time consuming and require a high degree of skill on behalf of the operator. Systems for automated cell count are therefore in demand, but most techniques are based on labelling cells with a dye. Here we show that digital holography may be used

Correspondence to: Dr. Kersti Alm. e-mail: kersti.alm@cob.lu.se for label-free and non-invasive cell counting directly in cell culture vessels with adherent viable cells.

Holography is a method of recording 3D information of an object with the help of interfering wave fronts from a laser or other coherent light sources. The field has undergone a paradigm shift with the advent of digital holography where the image is recorded on a digital image sensor (CCD or CMOS) and processed in a computer, instead of being developed on a photographic plate. The interference pattern recorded by the image sensor compresses the 3D information of the object into a single image, something which makes digital holography well suited for remote control of focusing, magnification and analysis. Focusing in the reconstruction algorithm also makes the system very suitable for automated image acquisition. Digital holography gives information of the phase shift $(\Phi)$ of the laser light that has been reflected or transmitted through the object. The phase shift can be translated to optical thickness, $L$, which usually can be measured in nanometer resolution and is determined by the object refractive index $(n)$, the wavelength $(\lambda)$ and the thickness $(t)$ according to:

$$
\Phi=\frac{2 \pi}{\lambda} \cdot L=\frac{2 \pi}{\lambda} \cdot \int_{0}^{t} n(z) \cdot d z
$$

The use of digital holography has recently been expanded to microscopy (Cuche et al., 1999; Schnars \& Jüptner, 2002; Gustafsson \& Sebesta, 2004; Gustafsson et al., 2004; Ferraro et al., 2005) especially in the field of cell biology analysis (Carl et al., 2004; Mann et al., 2005; Rappaz et al., 2005; Charrière et al., 2006; Kemper et al., 2006, http://www.lynceetec.com, http://www.photonics.com/content/news/2007/March/26/ 86999.aspx)

The traditional bright field microscopes have difficulties in differentiating and visualizing individual cells due to their low 
contrast properties, which tend to make the cells blend into the surrounding background. This has led to the development of various types of phase contrast techniques, which are widely used today in live cell imaging studies and cell cycle studies, allowing studies to be performed without the use of any chemical staining. Nevertheless, these techniques cannot be used for direct quantitative measurements that enable determination of either refractive index or optical thickness variations (Mann et al., 2005). However, digital holography can provide both quantitative and qualitative phase information from a single hologram (Marquet et al., 2005; Parshall \& Kim, 2006), which is the reason for the increasing interest in the technique in biological research. Today, applications for digital holography are expanding in cell monitoring in general (Carl et al., 2004; Rappaz et al., 2005; Charrière et al., 2006) and cancer research in particular (Yu et al., 2004; Dubois et al., 2006; Kemper et al., 2006; Hernandez-Montes Mdel et al., 2007).

Many scientific reports and projects in medicine and biology today have in common the fact that they estimate cell numbers during the course of the experiments. Traditionally cell counting is performed manually using a haemocytometer to count cells in suspension. Trypan blue has commonly been added to make cells more visible and to distinguish between live and dead cells. Over the last decade more sophisticated staining methods have been developed for accurate and automatic cell counts, using both direct and indirect measurements of cell numbers. However, it is known that direct staining of cells can interfere with both viability and function as the dyes react with macromolecules of the cells.

Methods for direct automated cell counting are often variations of particle counting and cell nuclear counting techniques. For these techniques to work, cells have to be in suspension, and for the many adherent cells lines used this means that the cells have to be detached from their growing surfaces. Automated cell counting based on optical image analysis offers non-invasive alternatives. The 'Cellscreen' system was developed a few years ago, working without staining and based on traditional phase contrast. Even though it is able to produce automated microscopic images, the analysis is, in the case of adherent cells, limited to confluence measurements (Brinkmann et al., 2002).

The recently constructed microscope Holomonitor ${ }^{\mathrm{TM}}$ M2 (Phase Holographic Imaging AB, Lund, Sweden) combines digital holography with the commonly used phase contrast microscope, thereby combining traditional light imaging with the possibility of achieving quantitative information on cellular shape, area and optical thickness. This project aims at determining the accuracy and repeatability of cell counting measurements using digital holographic microscopy compared to a conventional manual cell counting method using a haemocytometer. The collected data were also used to determine cell sizes and individual optical path lengths relative to the surrounding medium.

\section{Materials and methods}

\section{Microscope}

Holomonitor ${ }^{\mathrm{TM}} \mathrm{M} 2$ combines phase contrast microscopy with digital holography. The laser used is a $0.8 \mathrm{~mW}$ HeNe laser (633 nm). As the laser intensity is only approximately $10 \mathrm{~W} \mathrm{~m}^{-2}$ during imaging and the exposure time is less than $5 \mathrm{~ms}$, it is assumed that the laser irradiation has only minimal effects on the physiological functions of the cells. The short exposure time makes the method robust and insensitive to vibrations. The three dimensions of the object under study are recorded in one hologram and it is therefore possible to perform remote analysis (focusing, magnification) of the image with only a single hologram transferred between the instrument and the analysis computer. Phase contrast images were used as a reference to confirm that the cells were in a good condition.

\section{Software}

A fully automated imaging algorithm is used to compute amplitude and phase images from the acquired hologram. The algorithm is based on a standard Fresnel approximation (Cuche et al., 1999). The image is focused at infinity where the image is spatially filtered to eliminate the virtual image and zero term and simultaneously down sample and centre the real image. Secondly, the focus plane is automatically estimated by quadratic minimization of the variance of the amplitude image (Dubois et al., 2006). The phase image at the focal plane is unwrapped using Flyn's unwrapping algorithm (Ghiglia \& Pritt, 1998) and fitted to a second-order polynomial to construct an approximately planar background (Sebesta \& Gustafsson, 2005). The measurement noise creates a random phase shift around the background level whereas the cells produce large positive phase shifts superimposed on the noisy background. The background level is estimated by fitting the negative phase shifts to a Gaussian distribution.

\section{Cell lines}

Description of cell lines. Four different adherent cell lines were analysed in this study; MCF-10 A, L929, PC-3 and DU-145. MCF-10 A (human breast epithelia cells, American Type Culture Collection [ATCC], Manassas, VA, U.S.A.) were cultured in phenol-red-positive RPMI 1640 medium supplemented with 10\% heat-inactivated foetal calf serum (FCS), 1\% penicillin and streptomycin, 1\% non-essential amino acids, $10 \mu \mathrm{g} \mathrm{mL}^{-1}$ insulin, $20 \mathrm{ng} \mathrm{\textrm {mL } ^ { - 1 }}$ epidermal growth factor (Biochrome, Berlin, Germany), 100 $\mathrm{ng} \mathrm{mL}^{-1}$ cholera toxin and $500 \mathrm{ng} \mathrm{mL}^{-1}$ hydrocortisone (Sigma-Aldrich). DU-145 (human prostate cancer cells, ATCC) were cultured in DMEM medium $\left(4.5 \mathrm{~g} \mathrm{~L}^{-1}\right.$ glucose with sodium pyruvate and glutamine) supplemented with 


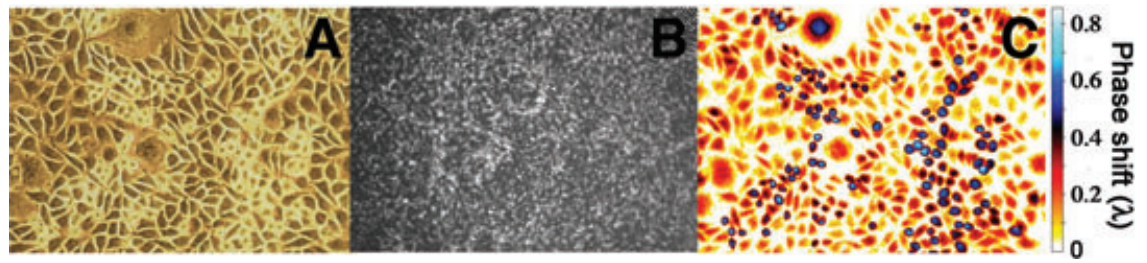

Fig. 1. L929 cells captured by Holomonitor ${ }^{\mathrm{TM}}$ M2. (A) Phase contrast image. (B) The same field of view but the laser interference pattern is captured using digital holography. (C) The unwrapped phase image of the interference pattern seen in B. The color scale indicates optical path length in terms of wavelength $(633 \mathrm{~nm})$, i.e. the phase shift. The picture field is approximately $0.5 \mathrm{~mm}$.

$10 \%$ heat-inactivated FCS and $1 \%$ penicillin and streptomycin. L929 (mouse fibroblast cells, ATCC) were cultured in phenolred-positive RPMI 1640 medium suspended with $10 \%$ heatinactivated FCS, $1 \%$ penicillin and streptomycin and 1\% glutamine (Biochrome). PC-3 cells (human prostate cancer cells, ATCC) were cultured in DMEM supplemented with 10\% FCS and $1 \%$ penicillin and streptomycin.

Seeding of cells. Cells were seeded at a density of $0.6 \times 10^{6}$ cells in a $75 \mathrm{~cm}^{2}$ tissue culture flask ( $\mathrm{Nunc}^{\mathrm{TM}}$, Roskilde, Denmark) in $15 \mathrm{~mL}$ of culture medium. The cells were incubated at $37^{\circ} \mathrm{C}$ in a water-saturated atmosphere with $5 \% \mathrm{CO}_{2}$ in air. Duplicate samples were counted once a day for 3 or 4 days. This was repeated twice for each cell line. The cell number was first determined with the microscope Holomonitor ${ }^{\mathrm{TM}} \mathrm{M} 2$, then manually using a standard haemocytometer.

\section{Determination of cell proliferation using images captured by} Holomonitor $^{\mathrm{TM}} \mathrm{M} 2$

The amount of cells in one flask was determined by capturing several images for each sample. First a phase contrast image was captured as reference, and then several holographic images. The captured image of the interference pattern (Fig. 1B) was mathematically converted to a representation of phase shift (Fig. 1C), resulting in a recognizable image. The total phase shift, according to Eq. (1), enables calculations of cellular optical thickness. The area in the cell culture flask that was covered by cells was also calculated in order to determine the degree of confluence. According to Eq. (1), the phase shift depends on both cell thickness (and hence volume), and refractive index. The refractive index of a cell may vary with both the amount of cellular components and their distribution and concentration within the cell. Thickness and refractive index can be measured separately by any method of decoupling (Rappaz et al., 2005). In each image, cells were also segmented in order to determine cell number and individual cell area and thickness. The segmentation software operates by morphological image analysis, using functions from the MATLAB ${ }^{\circledR}$ toolbox, e.g. watershed (Hernandez et al., 2006) to automatically locate each cell nucleus and cell body. The number of cells per image, i.e. per area unit was counted (Fig. 2). Segmentation required more computational time (in the order of seconds, depending on the number of cells) than measurement of the phase shift.

\section{Manual cell proliferation determination}

Two persons performed manual counting of cells using haemocytometers. To assure that no cells were washed away after the photographing, something which would affect the cell numbers for the manual counting, cells were not rinsed after removal of culture medium. Instead the cell cultures were incubated directly in trypsin. When all cells had been detached, complete cell culture medium was added and the cells were counted. Both dead and live cells were counted. Using trypan
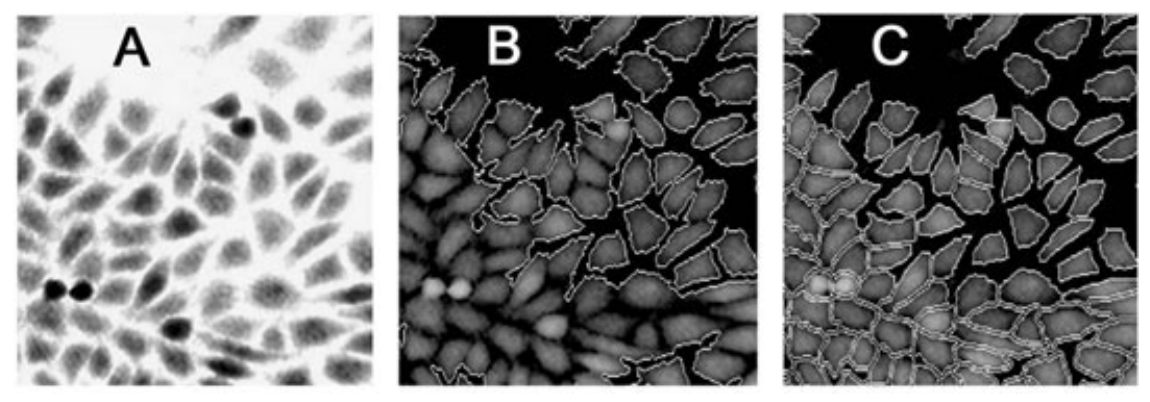

Fig. 2. Cells were captured by digital holography. After computer reconstruction the images were segmented in order to perform a cell count. (A) Digital holographic image of L929 cells, (B) cells automatically detected and (C) segmented by the segmentation software. Picture field is approximately $200 \mu \mathrm{mm}$. 
blue exclusion, the amount of dead cells was estimated to less than $5 \%$.

\section{Statistical methods}

We have used standard deviation calculations. All experiments were repeated twice with duplicate samples. For the cell proliferation studies at least 15 images per sample were captured. For the statistical study the number of images per sample are given in the diagrams.

\section{Results}

Figures 3-6 show how cell proliferation determinations based on the three different parameters calculated by computer algorithms correlated with cell proliferation determinations based on manual cell counting. A correlation for all four cell lines was determined by least-squares fitting. In Figs 5 and 6 , day 4 was not included in the least-square fitting, as the cell cultures at that time point had reached too high confluence levels. At 100\% confluence there is no free surface area that can be used for base line settings, something that makes correct phase shift calculations impossible. All three computer-based methods as well as the reference method, gave rise to similar growth curves (Fig. 7), further indicating that the three parameters stemming from digital holography gave the same results as manual cell count. Only growth curves for L929 cells are shown, but for all cell lines used in this study, growth curves obtained using all four measuring methods (results not shown) were similar.

In order to determine the number of images that were necessary to capture and compute for each sample to achieve a statistically significant cell amount determination we performed statistical calculations using between 3 and 18 images (Fig. 8A). We show data collected for L929 cells 2 days after seeding. The images were analysed for their total phase shift. The relative error decreased with an increasing amount of images. We also performed statistical calculations on L929 cells day 2 after seeding to determine how the standard deviation between samples varied as a function of the number of images captured for each sample (Fig. 8B). With 15 images captured for each sample, standard deviations ranged from less than $5 \%$ for confluence determinations to less than $10 \%$ for determinations of the cellular optical thickness.

Using digital holography, cell area and cellular optical thickness of single cells can be determined (Fig. 9). For L929 cells, the cell area decreased slightly during days 1-4 after seeding, whereas the optical thickness clearly decreases.

\section{Discussion}

Holomonitor ${ }^{\mathrm{TM}} \mathrm{M} 2$ is a versatile instrument that combines the traditional phase contrast microscope with digital holography. Here we show that digital holography enables us to measure
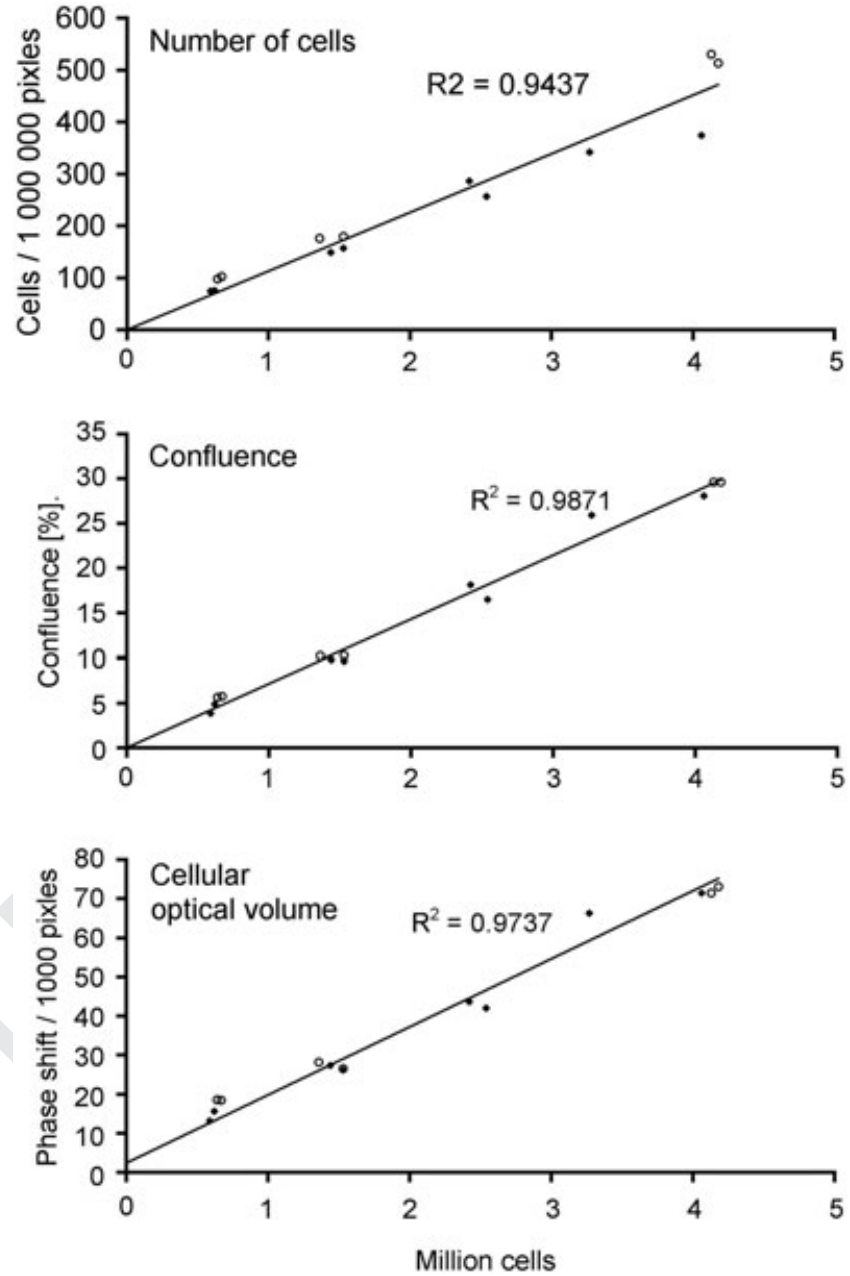

Fig. 3. PC-3 cells were counted by computer using three different calculation methods. The results were correlated with manual counting. (A) Correlation between the number of PC-3 cells per area unit, as obtained directly in the cell culture flask via computer algorithm, and a manual cell count. (B) Correlation between the confluence of PC-3 cells, as obtained directly in the cell culture flask via computer algorithm, and a manual cell count. (C) Correlation between cellular optical volume of PC-3 cells per area unit, as obtained directly in the cell culture flask via computer algorithm, and a manual cell count. The correlation is based on two separate experiments (o and $\diamond$, respectively) where two T75 cell culture flasks with cells were counted each day for 4 days, with the exception of day 3, when only data from one experiment, i.e. a total of two flasks, is available. For each value approximately 15 images have been analysed with 100-1400 cells per image.

cell number directly in cell culture vessels, but also to retrieve information on the area and optical thickness of the adherent cell population. We also demonstrate the possibility to use image processing to achieve information about individual cells. This information may be very useful in studies of cell condition, differentiation and cellular viability.

In this investigation, we focused on examining the possibilities to detect growth of adherent cells in three different 

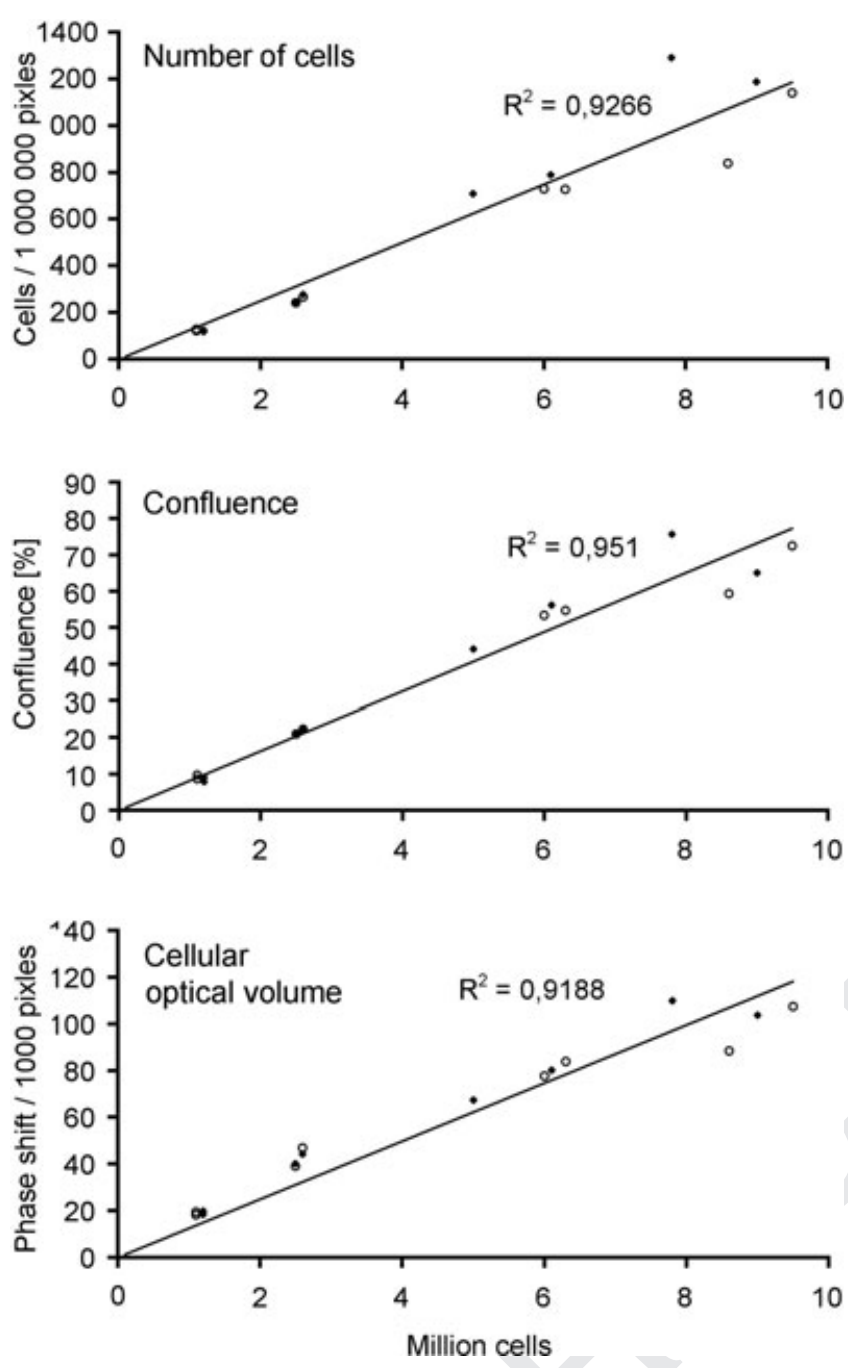

Fig. 4. L929 were counted by computer using three different calculation methods. The results were correlated with manual counting. (A) Correlation between the number of L929 cells per area unit, as obtained directly in the cell culture flask via computer algorithm, and a manual cell count. (B) Correlation between the confluence of L929 cells, as obtained directly in the cell culture flask via computer algorithm, and a manual cell count. (C) Correlation between cellular optical volume of L929 cells per area unit, as obtained directly in the cell culture flask via computer algorithm, and a manual cell count. The correlation is based on two separate experiments (o and $\$$, respectively) where two T75 cell culture flasks with cells were counted each day for 4 days. For each value approximately 15 images have been analysed with 100-1400 cells per image.

ways using digital holography. Degree of confluence was determined by calculating the area covered by cells in the culture flask. The total phase shift caused by the cells was also determined, enabling calculations of cellular optical thickness. Cells were finally segmented in order to determine cell number and the properties of individual cells. The three growth curves generated from the digital holography data correlate
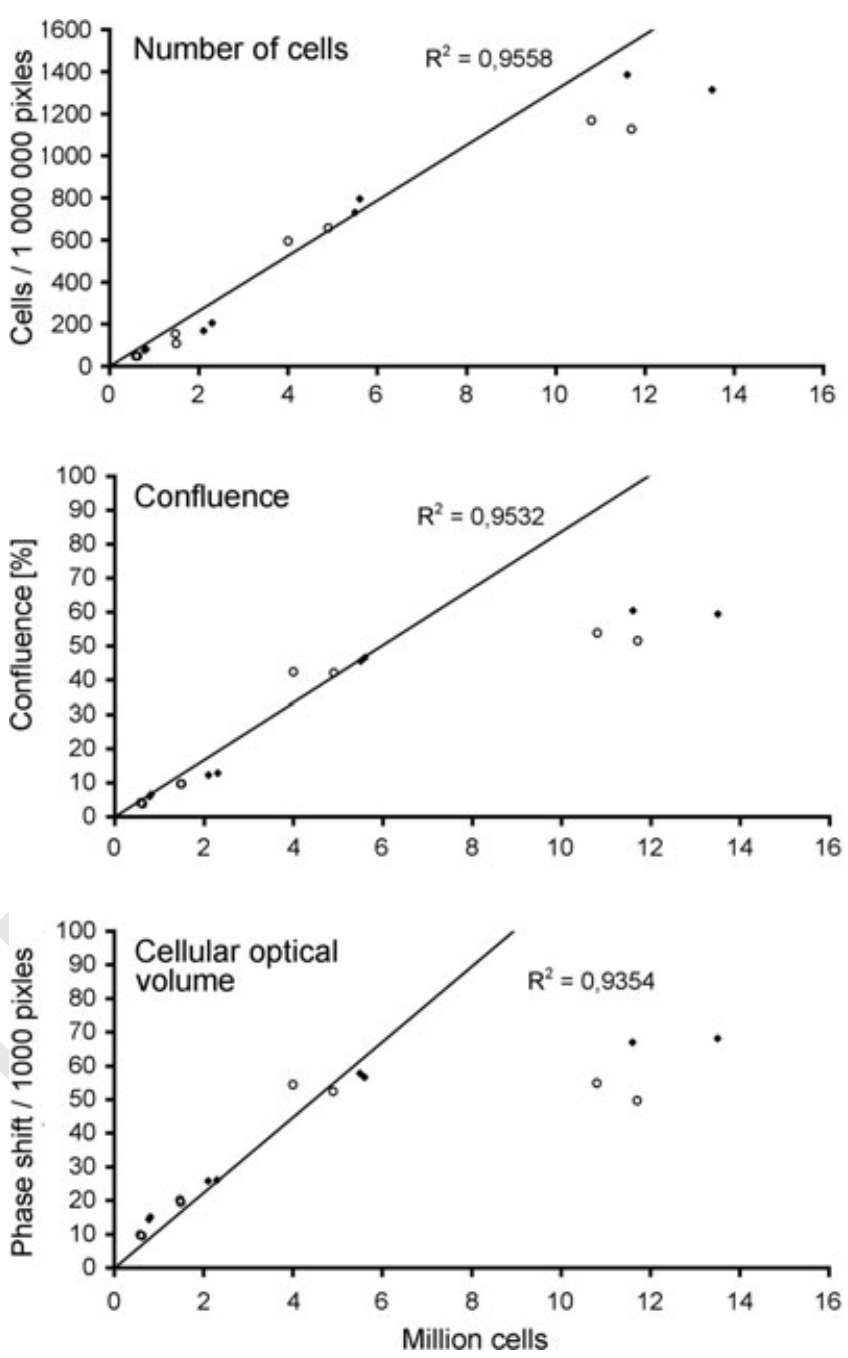

Fig. 5. DU-145 were counted by computer using three different calculation methods. The results were correlated with manual counting. (A) Correlation between the number of DU-145 cells per area unit, as obtained directly in the cell culture flask via computer algorithm, and a manual cell count. (B) Correlation between the confluence of DU-145 cells, as obtained directly in the cell culture flask via computer algorithm, and a manual cell count. (C) Correlation between optical volume of DU145 cells per area unit, as obtained directly in the cell culture flask via computer algorithm, and a manual cell count. The correlation is based on two separate experiments (o and $\$$, respectively) where two T75 cell culture bottles with cells were counted each day for 4 days. For each value approximately 15 images have been analysed with 100-1400 cells per image. Linear regression was made using data from the first 3 days only.

well with growth curves obtained by manual cell counting. Measurements of confluence are a well-known cell growth parameter. We have shown that also the optical path length or phase shift of cell cultures can be used. In our opinion, optical path length is a more accurate indication of actual cell growth, because it also takes into account changes of cell thickness or density. This indicates that any of the three 

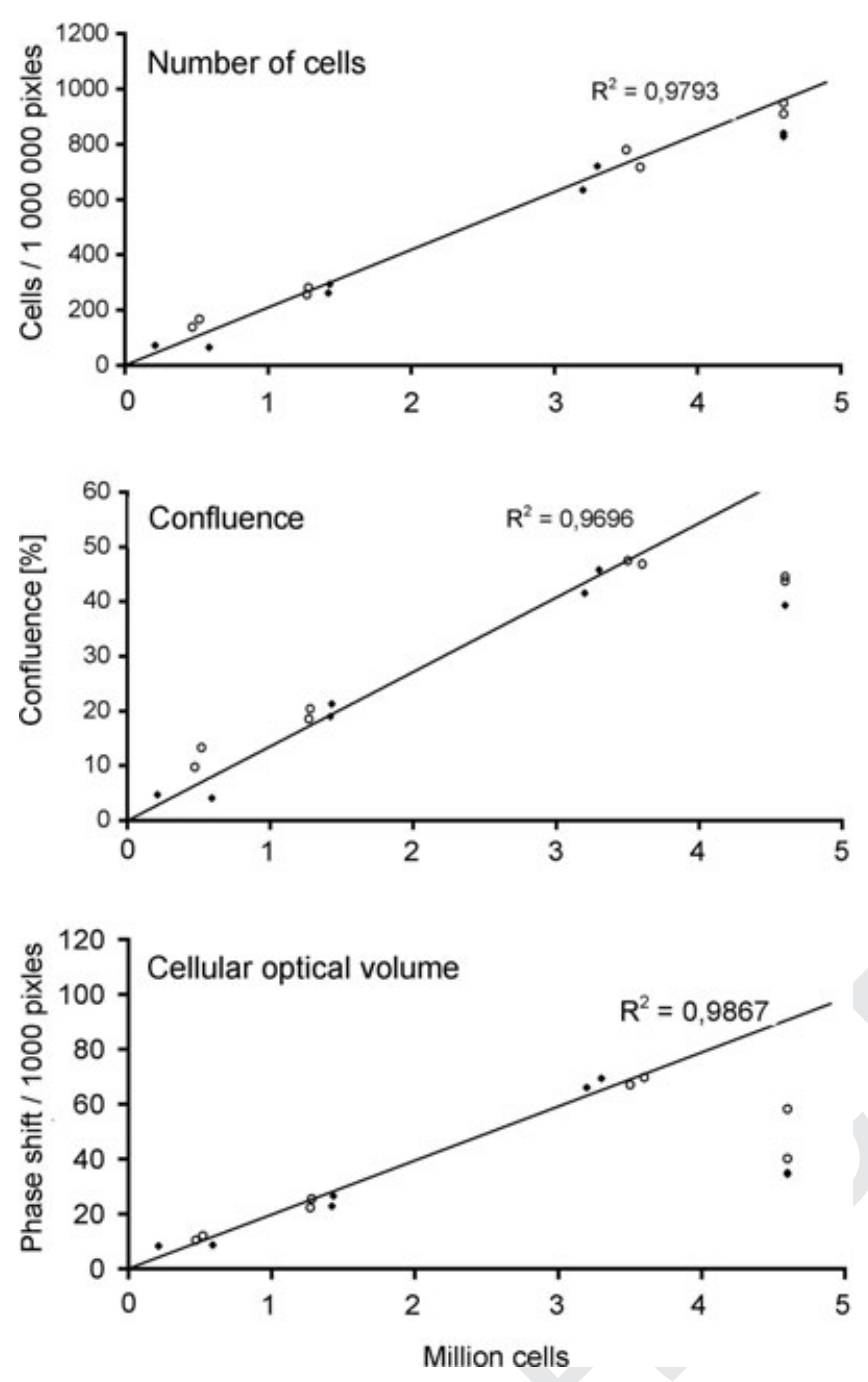

Fig. 6. MCF-10 A were counted by computer using three different calculation methods. These results were correlated with manual counting. (A) Correlation between the number of MCF-10 A cells per area unit, as obtained directly in the cell culture flask via computer algorithm, and a manual cell count. (B) Correlation between the confluence of MCF-10 A cells, as obtained directly in the cell culture flask via computer algorithm, and a manual cell count. (C) Correlation between optical volume of MCF10 A cells per area unit, as obtained directly in the cell culture flask via computer algorithm, and a manual cell count. The correlation is based on two separate experiments (o and $\downarrow$, respectively) where two T75 cell culture flasks with cells were counted each day for 4 days. For each value approximately 15 images have been analysed with 100-1400 cells per image. Linear regression was made using data from the first 3 days only.

digital holography parameters can be used to determine cell proliferation. These parameters can be extracted from a single set of collected data, thus making it possible to decide after the experiment which parameter to use. All information is stored automatically, making it possible to access and re-evaluate the information after the experiment. Counting each individual cell using the segmentation algorithm adds to the computation
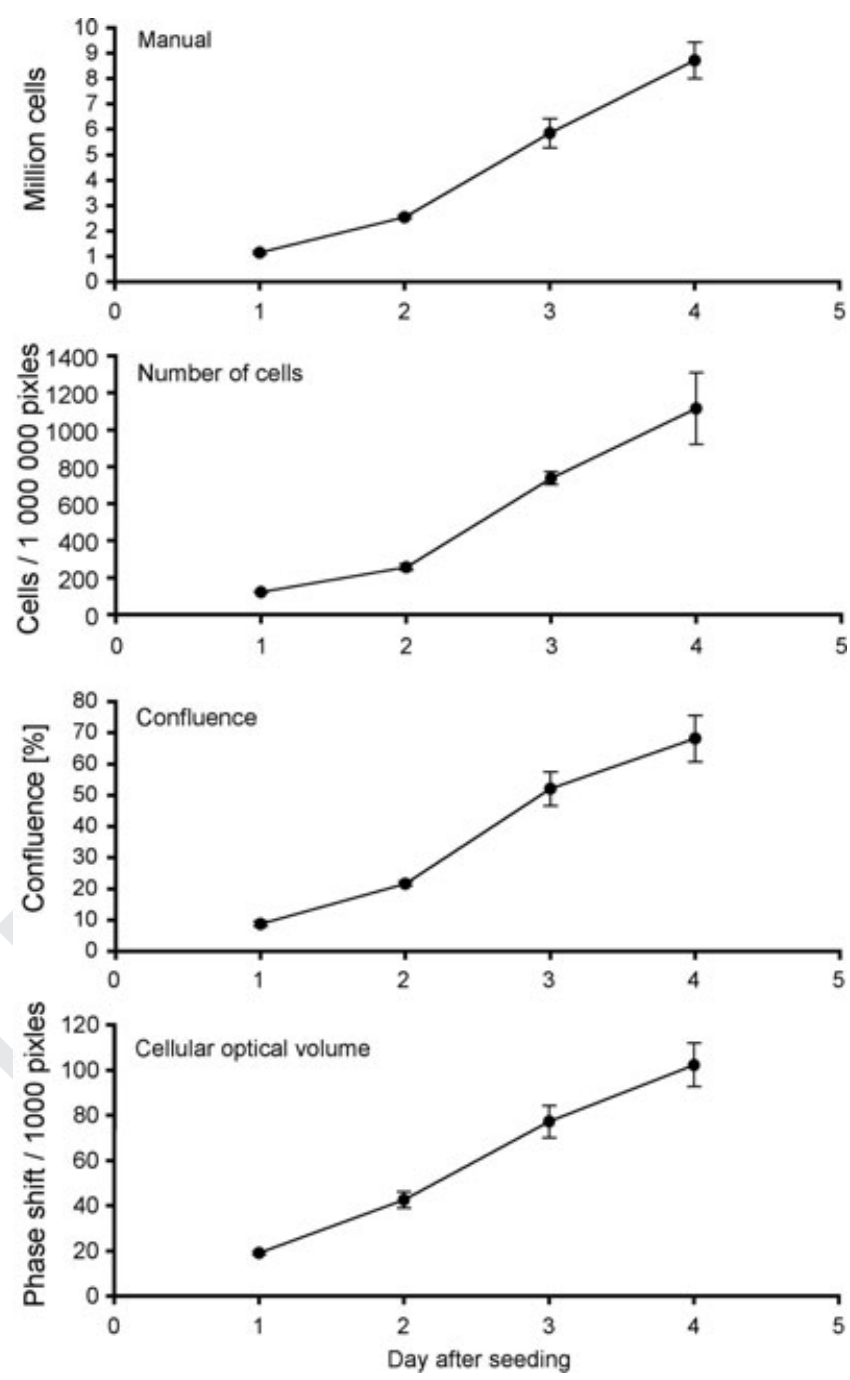

Fig. 7. Growth curves for L929, obtained via (A) manual count, (B) computer calculation of number of cells using segmentation (C) degree of confluence, (D) the cellular optical volume as determined by the ability of the cells to shift the phase of the laser light. The lines represent a mean value of four points, obtained in two separate experiments total. Standard deviations have been indicated.

time, but may prove useful in some cases, because it allows for categorization and analysis of properties such as area and shape of each individual segmented body.

The three different cell growth parameters measured by digital holography in this study result in growth curves with standard deviations of $5-10 \%$. Manual cell counting is labour intensive and time consuming, and also gives standard deviations of $5-10 \%$, by skilled operators. By counting cells directly in the culture vessels using digital holography, we see a number of benefits. For adherent cells, no preceding work to detach the cells is required in order to count the cells. Because the technique is non-destructive, the same sample can be used for sequential measurements, thus eliminating the necessity 

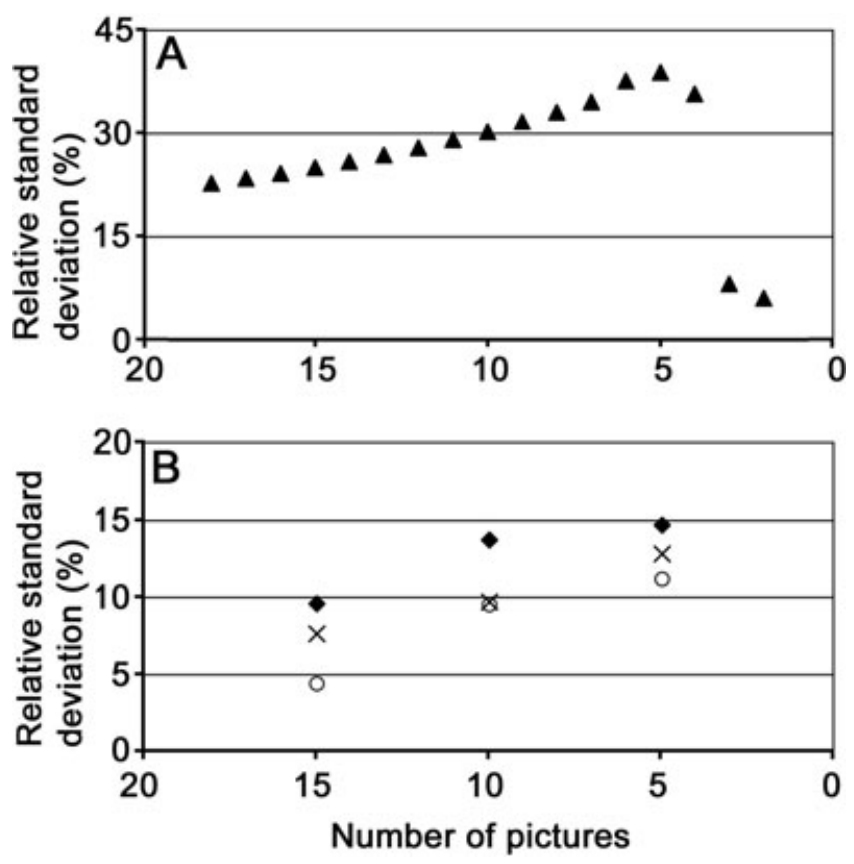

Fig. 8. Determination of relative errors when determining the amount of L929 cells per area unit, using phase shift data obtained via computer algorithms. (A) The relative error between images as a function of the number of images was calculated. For most calculations, 15-20 pictures were used, giving a relative standard deviation of less than $30 \%$. (B) The relative error between four cell culture flasks was calculated, as a function of the number of pictures used in the calculation. The three data sets represent three different methods to determine the amount of cells in a cell culture flask, namely number of cells $(x)$, confluence (o) and cellular optical volume $(\diamond)$. For most calculations, more than 15 pictures were used, giving a relative standard deviation of less than $10 \%$.

to have separate samples for each time point. A typical manual count takes approximately 20 min effective lab time. In our case the time for reconstruction and image analysis varies from $20 \mathrm{~s}$ up to just under $1 \mathrm{~min}$, depending on the number of cells in one picture. However, it is only the recording, and not the computation, of the images that requires human supervision. To record a set of digital holography images takes less than a minute. The imaging speed, which is typically in the order of milliseconds, is limited only by the performance of the imagerecording sensor. The computation time is limited by the speed of the computer and the algorithms used.

It is evident that with a computation of the confluence and the number of cells, results can only be obtained from samples where cell confluence is less than $100 \%$. By using the phase shift it is theoretically possible to calculate a correct value of cellular content, even with cells growing in many layers, but it is essentially to find a free area for correct base line setting. Because the measured property, the phase shift, is cyclic by $2 \pi$, according to Eq. (1), the placement of the background level where $L=0$, can be set arbitrarily. With the algorithms used in this setup, it was not possible to accurately establish
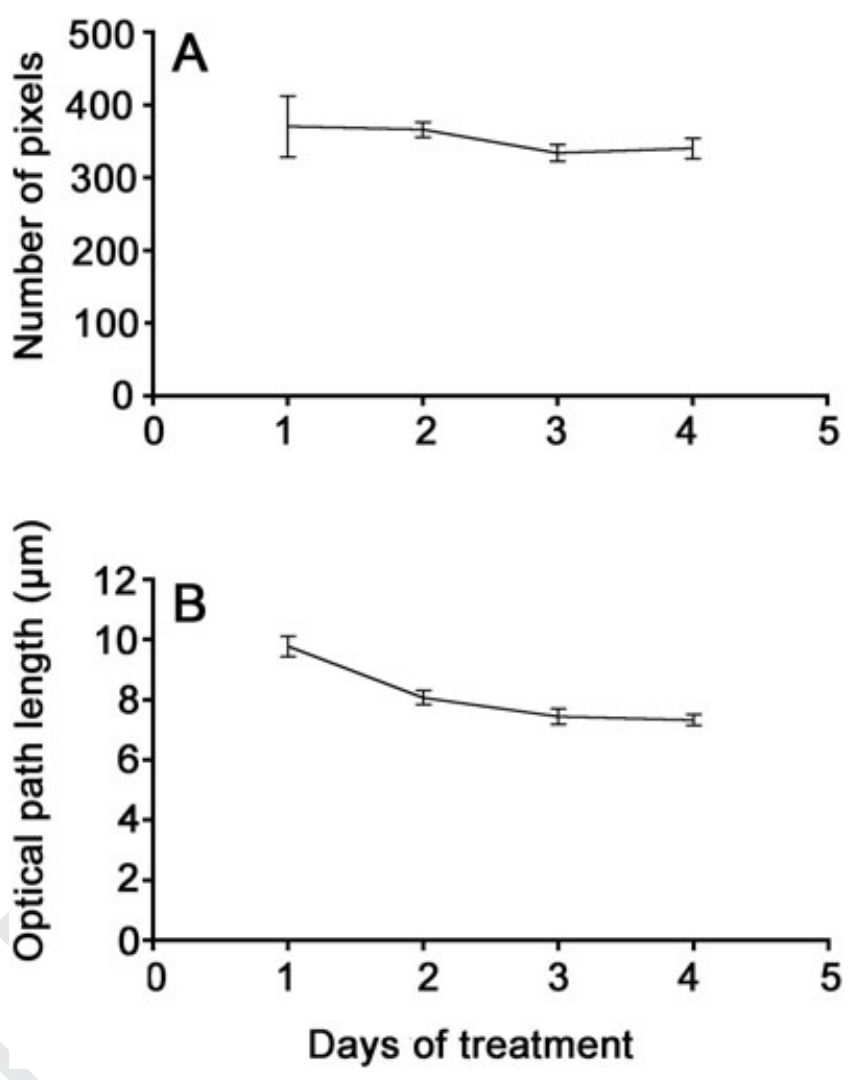

Fig. 9. Determination of average cell area and cellular optical thickness in PC-3 cells days 1-4 after seeding as calculated using holographic images and computer algorithms. (A) Cell area. (B) Cellular (optical) thickness. Lines represent mean value. Bars represent standard deviations. For each value approximately 15 images have been analysed with 100-1400 cells per image.

a correct base line for a continuous multi-cellular layer. One way to circumvent this problem is to calibrate the system using an area in a culture vessel with no attached cells as reference.

In this study, we have evaluated cell counting and analysis of adherent cells. Because adherent cells must be detached from the cell culture vessel before manual counting is possible, an automatic counting may prove very time and labour saving. We see no practical limit for using this technique for cells in suspension as well, and we are currently expanding our investigations to include this field. The reported results have all been obtained from cells cultured in $75 \mathrm{~cm}^{2}$ cell culture flasks, but any kind of cell culture vessel may be used, including smaller flasks, Petri dishes and many types of multi-well plates (results not shown).

In conclusion, we have used a unique non-invasive labelfree cell counting method, achieving results comparable to conventional cell counting using a haemocytometer. The major advantage using Holomonitor ${ }^{\mathrm{TM}} \mathrm{M} 2$ is the opportunity to easily access information about cell number, size, optical thickness and confluence in an automatic, non-invasive manner. 


\section{References}

Brinkmann, M., Lütkemeyer, D., Gudermann, F. \& Lehmann, J. (2002) New technologies for automated cell counting based on optical image analysis 'The Cellscreen'. Cytotechnology 38, 119-127.

Carl, D., Kemper, B., Wernicke, G. \& von Bally, G. (2004) Parameteroptimized digital holographic microscope for high-resolution living-cell analysis. Appl. Opt. 43, 6536-6544.

Charrière, F., Pavillon, N., Colomb, T. et al. (2006) Living specimen tomography by digital holographic microscopy: morphometry of testate amoeba. Opt. Express 14, 7005-7013.

Cuche, E., P., M. \& C., D. (1999) Simultaneous amplitude-contrast and quantitative phase-contrast microscopy by numerical reconstruction of Fresnel off-axis holograms. Appl. Optics 38, 6994-7001.

Dubois, F., Yourassowsky, C., Monnom, O. et al. (2006) Digital holographic microscopy for the three-dimensional dynamic analysis of in vitro cancer cell migration. J. Biomed. Opt. 11, 054032.

Ferraro, P., Grilli, S., Alfieri, D. et al. (2005) Extended focused image in microscopy by digital holography. Opt. Express 13, 6738-6749.

Ghiglia, D.C. \& Pritt, M.D. (1998) Two-Dimensional Phase Unwrapping: Theory, Algorithms, and Software. Wiley, New York.

Gustafsson, M. \& Sebesta, M. (2004) Refractometry of microscopic objects with digital holography. Appl. Opt. 43, 4796-4801.

Gustafsson, M., Sebesta, M., Bengtsson, B., Pettersson, S.G., Egelberg, P. \& Lenart, T. (2004) High-resolution digital transmission microscopy a Fourier holography approach. Opt. Lasers Eng. P.53-563.

Hernandez, L., Gothreaux, P., Shih, L. \& Campbell, G. (2006) Toward real-time biopsy image analysis and cell segmentation. IPCV'06: Proc. $81-87$.
Hernandez-Montes Mdel, S., Perez-Lopez, C. \& Santoyo, F.M. (2007) Finding the position of tumor inhomogeneities in a gel-like model of a human breast using 3-D pulsed digital holography. J. Biomed. Opt. 12, 024027.

Kemper, B., Carl, D., Schnekenburger, J., Bredebusch, I., Schafer, M., Domschke, W. \& von Bally, G. (2006) Investigation of living pancreas tumor cells by digital holographic microscopy. J. Biomed. Opt. 11, 34005.

Mann, C.J., Yu, L., Lo, C.-M. \& Kim, M.K. (2005) High-resolution quantitative phase-contrast microscopy by digital holography. Opt. Express 13, 8693-8698.

Marquet, P., Rappaz, B., Magistretti, P.J.,Cuche,E., Emery, Y.,Colomb, T.\& Depeursinge, C. (2005) Digital holographic microscopy: a noninvasive contrast imaging technique allowing quantitative visualization of living cells with subwavelength axial accuracy. Opt. Lett. 30, 468-470.

Parshall, D. \& Kim, M.K. (2006) Digital holographic microscopy with dual-wavelength phase unwrapping. Appl. Opt. 45, 451-459.

Rappaz, B., Marquet, P., Cuche, E., Emery, Y., Depeursinge, C. \& Magistretti, P.J. (2005) Measurement of the integral refractive index and dynamic cell morphometry of living cells with digital holographic microscopy. Opt. Express 13, 9361-9373.

Schnars, U. \& Jüptner, W.P.O. (2002) Digital recording and numerical reconstruction of holograms. Meas. Sci. Technol. 13, R85-R101.

Sebesta, M. \& Gustafsson, M. (2005) Object characterization with refractometric digital Fourier holography. Opt. Lett. 30, 471-473.

Yu, P., Mustata, M., Peng, L., Turek, J.J., Melloch, M.R., French, P.M. \& Nolte, D.D. (2004) Holographic optical coherence imaging of rat osteogenic sarcoma tumor spheroids. Appl. Opt. 43, 4862-4873. 


\section{Queries}

Journal: JMI

Paper: jmi2095

Dear Author

During the copy-editing of your paper, the following queries arose. Please respond to these by marking up your proofs with the necessary changes/additions. Please write your answers on the query sheet if there is insufficient space on the page proofs. Please write clearly and follow the conventions shown on the corrections sheet. If returning the proof by fax do not write too close to the paper's edge. Please remember that illegible mark-ups may delay publication.

\begin{tabular}{|l|l|l|}
\hline $\begin{array}{l}\text { Query } \\
\text { Reference }\end{array}$ & Query & Remarks \\
\hline Q1 & Author: Please provide a set of keywords for this article. & \\
\hline Q2 & $\begin{array}{l}\text { Author: Please provide the telephone and fax numbers } \\
\text { of the 'correspondence' author. }\end{array}$ & \\
\hline Q3 & $\begin{array}{l}\text { Author: Please provide the detailed location (city, } \\
\text { country [if not USA]; city, state [if USA]) of } \\
\text { manufacturer 'Sigma-Aldrich'. }\end{array}$ & \\
\hline Q5 & $\begin{array}{l}\text { Author: Please provide the expansion of 'DMEM' in the } \\
\text { sentence 'DU-145 (human... }\end{array}$ & \\
\hline Q6 & $\begin{array}{l}\text { Author: Please check the suggested running head. } \\
\text { available) in reference Dubois et al. (2006). }\end{array}$ & \\
\hline Q7 & $\begin{array}{l}\text { Author: Please check the correctness of the given page } \\
\text { range in reference Gustafsson et al. (2004). }\end{array}$ & \\
\hline Q8 & $\begin{array}{l}\text { Author:Please provide the location of the 'proceedings' } \\
\text { in reference Hernandez et al. (2006). }\end{array}$ & \\
\hline Q9 & $\begin{array}{l}\text { Author: Please provide the complete page range (if } \\
\text { available) in references Hernandez-Montes Mdel et al. } \\
\text { (2007) and Kemper et al. (2006). }\end{array}$ & \\
\hline
\end{tabular}




\section{Please correct and return this set}

Please use the proof correction marks shown below for all alterations and corrections. If you wish to return your proof by fax you should ensure that all amendments are written clearly in dark ink and are made well within the page margins.

\begin{tabular}{|c|c|c|}
\hline Instruction to printer & Textual mark & Marginal mark \\
\hline Leave unchanged & ... under matter to remain & (D) \\
\hline $\begin{array}{l}\text { Insert in text the matter } \\
\text { indicated in the margin }\end{array}$ & $\Lambda$ & $\begin{array}{l}\text { New matter followed by } \\
h \text { or } h \times 2\end{array}$ \\
\hline Delete & $\begin{array}{l}\text { I through single character, rule or underline } \\
\text { or } \\
\longmapsto \text { through all characters to be deleted }\end{array}$ & $\sigma$ or $\sigma$ \\
\hline $\begin{array}{l}\text { Substitute character or } \\
\text { substitute part of one or } \\
\text { more word(s) }\end{array}$ & 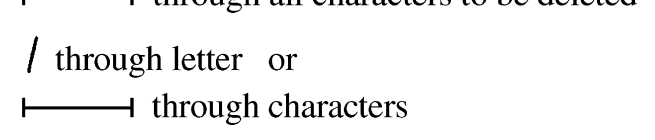 & $\begin{array}{l}\text { new character } / \text { or } \\
\text { new characters } /\end{array}$ \\
\hline Change to italics & — under matter to be changed & $\leftarrow$ \\
\hline Change to capitals & $\equiv$ under matter to be changed & $\equiv$ \\
\hline Change to small capitals & $=$ under matter to be changed & $=$ \\
\hline Change to bold type & $\sim$ under matter to be changed & $\sim$ \\
\hline Change to bold italic & $\bar{\sim}$ under matter to be changed & 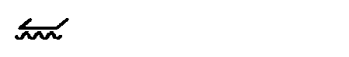 \\
\hline Change to lower case & Encircle matter to be changed & 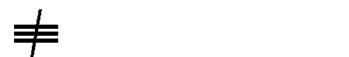 \\
\hline Change italic to upright type & (As above) & \\
\hline Change bold to non-bold type & (As above) & up \\
\hline Insert 'superior' character & $\begin{array}{l}\text { I through character or } \\
K \text { where required }\end{array}$ & $\begin{array}{l}y \text { or } y \\
\text { under character } \\
\text { e.g. } y \text { or } y^{2}\end{array}$ \\
\hline Insert 'inferior' character & (As above) & $\begin{array}{l}\text { h } \\
\text { over character } \\
\text { e.g. } \hat{L}\end{array}$ \\
\hline Insert full stop & (As above) & $\odot$ \\
\hline Insert comma & (As above) & \\
\hline Insert single quotation marks & (As above) & $\begin{array}{l}\dot{y} \text { or } \dot{X} \text { and/or } \\
\dot{y} \text { or } \dot{X}\end{array}$ \\
\hline Insert double quotation marks & (As above) & $\begin{array}{l}\ddot{y} \text { or } \ddot{x} \text { and/or } \\
\ddot{y} \text { or } \ddot{x}\end{array}$ \\
\hline Insert hyphen & (As above) & $1-1$ \\
\hline Start new paragraph & 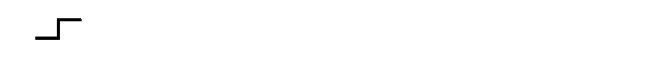 & 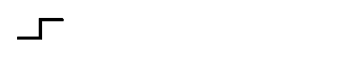 \\
\hline No new paragraph & $\sim$ & $\sim$ \\
\hline Transpose & $\sqcup$ & $\sqcup$ \\
\hline Close up & linking $\bigcirc$ characters & $\mathcal{J}$ \\
\hline $\begin{array}{l}\text { Insert or substitute space } \\
\text { between characters or words }\end{array}$ & $\begin{array}{l}\text { I through character or } \\
\text { A where required }\end{array}$ & $Y$ \\
\hline $\begin{array}{l}\text { Reduce space between } \\
\text { characters or words }\end{array}$ & $\begin{array}{l}\text { between characters or } \\
\text { words affected }\end{array}$ & $\uparrow$ \\
\hline
\end{tabular}

